\title{
AVALIAÇÃO FISIOTERAPÊUTICA DOS SISTEMAS MASTIGATÓRIO E RESPIRATÓRIO DE UM PORTADOR DE SÍNDROME OTODENTAL: UM ESTUDO DE CASO
}

\author{
Silva FB, Sampaio LMM, Carrascosa AC \\ Curso de Fisioterapia, Departamento de Ciências Exatas e Naturais, Centro Universitário de Araraquara, Araraquara, SP \\ Correspondência para: Andréa Corrêa Carrascosa, Rua D. Pedro II, 614, Centro, Araraquara, SP, CEP 14801-040, e-mail: \\ acarrascosa@uniara.com.br
}

Recebido: 10/12/2004 - Aceito: 18/08/2005

\begin{abstract}
RESUMO
Introdução: Síndrome Otodental é uma síndrome autossômica rara de caráter dominante que apresenta como principais manifestações, anomalias dentárias e perda gradual da audição. Objetivos: Detectar através de avaliação fisioterapêutica alterações nos sistemas mastigatório, respiratório e postura corporal em uma portadora da Síndrome Otodental. Metodologia: Foram realizadas a avaliação postural e inspeção facial, palpação dos músculos mastigatórios e respiratórios, medidas de amplitude da articulação temporomandibular e cirtometria toracoabdominal, além de coleta de dados na anamnese. Resultados e Discussão: Foram observados respiração bucal associada a maior mobilidade da região axilar, e não foram encontrados sinais ou sintomas de desordens temporomandibulares. Os achados das características faciais e postura foram comuns aos de portadores de respiração bucal, sugerindo um desenvolvimento de alterações respiratórias secundárias à Síndrome Otodental. No entanto, a raridade desta patologia associada à descrição na literatura restrita a área odontológica, dificultam uma análise comparativa com os dados do presente estudo.
\end{abstract}

Palavras-chave: síndrome otodental, sistema mastigatório, sistema respiratório, postura.

\section{ABSTRACT \\ Physiotherapeutic Evaluation of Masticatory and Respiratory Systems in a Patient with Otodental Syndrome: A Case Study}

Background: Otodental syndrome is a rare autosomal syndrome of dominant characteristic in which dental anomalies and gradual loss of hearing are the main manifestations. Objective: To detect abnormalities in the masticatory and respiratory systems and posture of a patient with otodental syndrome, based on physiotherapeutic evaluation. Method: Posture was evaluated; facial inspection was performed; masticatory and respiratory muscles were palpated; temporomandibular joint range of movement was measured; and thoracoabdominal cirtometry was performed. Data were also obtained by anamnesis. Results and Discussion: Oral respiration was found to be associated with increased mobility in axillary region. No signs or symptoms of temporomandibular disorders were found. Facial and postural findings were common among patients presenting oral respiration, thus suggesting the development of respiratory alterations secondary to otodental Syndrome. However, the rarity of this pathological condition, together with descriptions in literature that are restricted to the field of dentistry, makes it difficult to comparatively analyze the data from the present study.

Key words: otodental syndrome, masticatory system, respiratory system, posture. 


\section{INTRODUÇÃO}

Síndrome Otodental ${ }^{1}$, também chamada Otodentodisplasia $^{2}$, Displasia Otodental ${ }^{3}$ e Globodontia ${ }^{4}$, foi citada como um tipo de displasia ectodérmica, com uma herança autossômica dominante de expressividade variável².

Alguns autores ${ }^{1,5,6}$ descrevem as coroas dos caninos e dentes posteriores alargadas, bulbosas e malformadas, com múltiplos lóbulos proeminentes. A relação entre cúspides e as principais fissuras entre os dentes são eliminadas (por isso, o uso do termo globodontia) ${ }^{1}$. Os dentes pré-molares são freqüentemente ausentes ou pequenos e ocorre, freqüentemente, erupção tardia com má-formação dos dentes posteriores decíduos e permanentes, além da perda da audição a altas freqüências ${ }^{1,2,3,4,6,7}$.

As alterações na dentição decídua são mais intensas, acarretando alterações faciais como anteversão das narinas, face alongada, um longo filtrum, bochechas protuberantes, mordida aberta anterior e contração dos músculos orbiculares e mentoniano na tentativa de fechar a boca, esta dificuldade muitas vezes leva o indivíduo a adotar uma mudança no padrão respiratório, a fim de facilitar as trocas gasosas, passando a utilizar assim, a respiração bucal ${ }^{4,6,8}$.

Para facilitar a passagem do ar pela cavidade oral é necessário o aumento do espaço funcional interoclusal. Para isto o indivíduo respirador bucal realiza o abaixamento mandibular e a extensão da cabeça prejudicando seu campo visual e, como compensação, ocorre a flexão cervical ${ }^{9}$. Estas sucessivas mudanças provocam desequilíbrios em todo sistema estomatognático, alterando a postura de repouso e as funções mastigação, fala e deglutição ${ }^{9}$.

Os respiradores bucais apresentam alterações no sistema estomatognático, que se manifestam na conformação e estrutura dos órgãos, fazendo com que o corpo saia de seu eixo, se estas alterações não forem detectadas a tempo, poderão transformar-se em deformidades esqueléticas degenerativas, provocando graves conseqüências ${ }^{10}$.

Este estudo tem por objetivo detectar possíveis alterações nos sistemas mastigatório, respiratório e na postura de um portador da Síndrome Otodental, e desta forma contribuir para o conhecimento científico sobre esta patologia.

\section{METODOLOGIA}

A metodologia a seguir foi submetida à avaliação e aprovada pelo Comitê de Ética em Pesquisa do Centro Universitário de Araraquara (protocolo no 252/2004).

Foi realizada, na Clínica de Fisioterapia do Centro Universitário de Araraquara, a avaliação fisioterapêutica de uma criança, 10 anos de idade, sexo feminino, portadora da
Síndrome Otodental. A avaliação foi realizada por um único examinador, previamente treinado.

A ficha de avaliação elaborada para este estudo foi dividida em anamnese e exame físico. Na anamnese foram colhidas informações sobre problemas respiratórios e alterações do sistema mastigatório como dor na articulação temporomandibular ou músculos mastigatórios, dores de cabeça e dificuldades na mastigação.

No exame físico foram realizadas inspeção geral da face, pescoço e tórax, avaliação postural, investigação do tônus dos músculos mastigatórios e respiratórios, avaliação da amplitude da articulação temporomandibular e cirtometria toracoabdominal. Todas as medidas foram realizadas três vezes, sendo considerada a média aritmética dos valores obtidos.

Na avaliação postural foram investigados a postura da cabeça e coluna cervical, posição de ombros e pelve e alterações das curvaturas da coluna. Na inspeção das características faciais foram observados a fisionomia, formato e altura da face, tônus muscular e assimetrias, e ainda, o padrão respiratório e o tipo de tórax ${ }^{12}$.

A palpação dos músculos acessórios da respiração ${ }^{12} \mathrm{e}$ dos músculos masseter e temporal ${ }^{11}$ foi realizada com o objetivo de determinar o tônus e a presença de dor muscular, e foi mensurada a amplitude dos movimentos da articulação temporomandibular com o auxílio de um paquímetro da marca Vonder ${ }^{11}$.

A determinação do tônus dos músculos intercostais e diafragma foram realizados e graduados segundo parâmetros e escala pré-determinada ${ }^{12}$.

A cirtometria toracoabdominal foi realizada utilizandose uma fita métrica nos níveis axilar, xifoideano e abdominal (cicatriz umbilical), sendo o diâmetro da caixa torácica mensurado no repouso respiratório e ao final da inspiração e expiração máximas ${ }^{12}$.

Para garantir a confiabilidade dos valores obtidos, todas as medidas foram realizadas duas vezes, utilizando-se a média dos valores obtidos.

\section{RESULTADOS E DISCUSSÃO}

Através dos dados colhidos na anamnese foi relatada perda gradual da audição detectada em avaliação otorrinolaringológica, o que representa um achado comum já descrito em outros estudos $1,2,3,4,6,7$, além do atraso na erupção dentária primária e secundáriaa ${ }^{2,4,6}$.

A voluntária relatou ainda ser portadora de alterações respiratórias como rinite alérgica e dificuldade na respiração nasal noturna. Sobre presença de hábitos parafuncionais do sistema mastigatório foram relatados roer unhas, morder tampas de caneta e apoiar o queixo na mão. 
À inspeção e nos registros fotográficos foi observada fisionomia inexpressiva, face alongada, anteversão das narinas, longo filtrum, lábio superior hipotônico, bochechas flácidas e hiperatividade do músculo mentoniano ao cerramento labial, características estas, encontradas em outros indivíduos portadores da Síndrome Otodental ${ }^{4}$ como também em respiradores bucais ${ }^{8,9,13}$ (Figura 1).

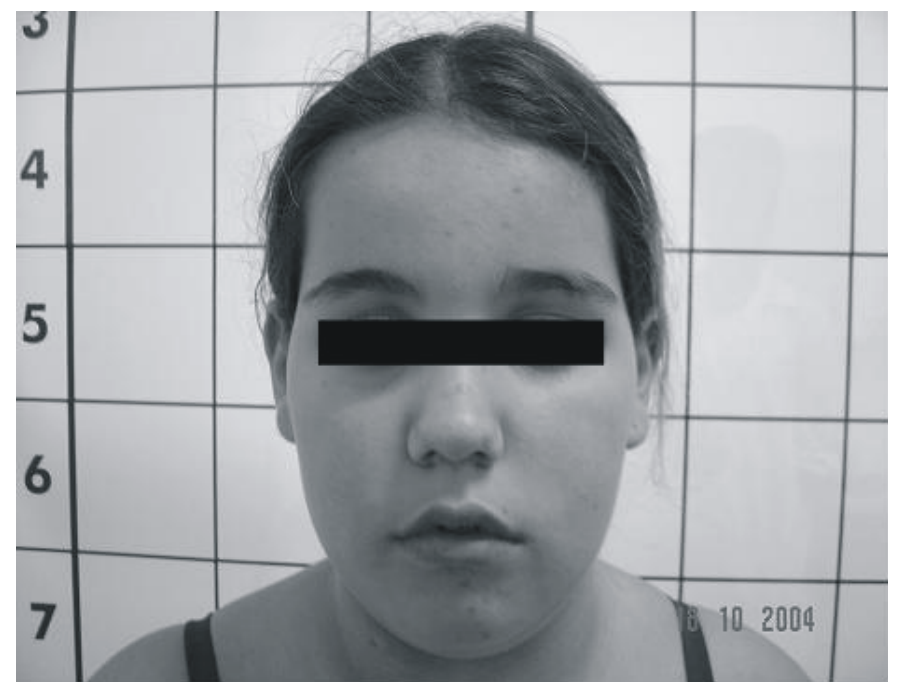

Figura 1. Alterações faciais. Nota-se fisionomia inexpressiva, face alongada, anteversão das narinas, longo filtrum, lábio superior hipotônico, bochechas flácidas e hipertonicidade do músculo mentoniano ao cerramento labial.

Foram encontradas ainda características posturais coincidentes com as encontradas em respiradores bucais, já citadas na literatura ${ }^{10,13}$ como a anteriorização da cabeça com retificação de coluna cervical, protrusão dos ombros, protrusão abdominal e hiperlordose lombar com anteversão pélvica (Figura 2).

A cirtometria tóraco-abdominal evidenciou uma maior mobilidade da região axilar, o que infere o padrão apical da respiração, não sendo, no entanto, encontradas alteração do tórax, anormalidades à palpação dos músculos acessórios da respiração, nem dos músculos intercostais e diafragma que foram classificados como "bons"12.

Não foram encontradas alterações do tônus dos músculos masseter e temporal à palpação, o que contradiz alguns achados da literatura sobre respiradores bucais ${ }^{13}$, nem restrição da amplitude mandibular. Foi encontrado apenas aumento da sensibilidade dolorosa bilateral do músculo masseter, possivelmente devido à presença dos hábitos parafuncionais $^{10}$.

Apesar de não terem sido encontrados sinais ou sintomas de desordens temporomandibulares, os hábitos parafuncionais são importantes fatores etiológicos de tais condições, podendo colaborar para o desenvolvimento das mesmas.

Os achados das características faciais e postura da voluntária são comuns aos de portadores de respiração bucal ${ }^{8,10}$, sugerindo um desenvolvimento de alterações respiratórias secundárias à Síndrome Otodental.

A relação encontrada entre as alterações dentárias associada a desvios posturais e respiração bucal requerem diagnóstico e intervenção precoce, objetivando minimizar suas conseqüências. Contudo, maiores estudos deverão ser realizados para garantir a confiabilidade dos achados em portadores de síndrome Otodental.

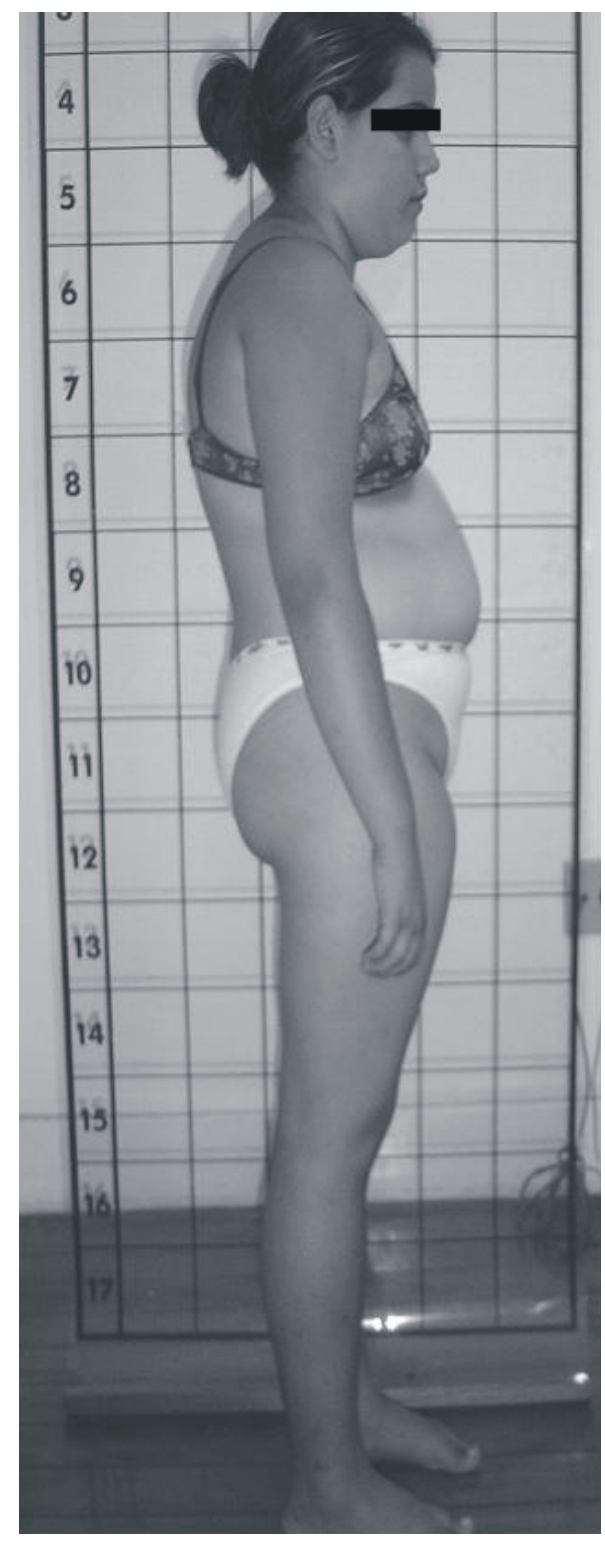

Figura 2. Alterações posturais. Nota-se anteriorização da cabeça com retificação cervical, protrusão dos ombros, protrusão abdominal, hiperlordose lombar e anteversão pélvica. 


\section{REFERÊNCIAS BIBLIOGRÁFICAS}

1. Gorlin RJ, Cohen MMJr, Hennekan RCM. Syndromes of Head and Neck. $3^{\text {a }}$ ed. Ed. New York: Oxford University Press; 2001 p. 859-77.

2. Levin LS, Jorgenson RJ. Familial otodentodysplasia: A "new” syndrome. Am. J. Human Genetic 1972 Philadelphia p. 61 a.

3. Jorgenson RJ, Marsh SJ, Farrigton FH. Otodental dysplasia. Birth Defects 1975; 11: 115-9.

4. Witkop CJJr. Globodontia in the otodental syndrome. Oral Path 1976; 41: 472-83.

5. Toledo AO, Bausells HII, Vono RMG, Rocca RA. Anomalia dental múltipla em três irmãos: Caso clínico. Rev. Fac. Farm. Odont. Araraquara 1971; 5: 207-14.

6. Santos-Pinto L, Oviedo MDO, Santos-Pinto A, Iost HI, Seale NS, Reddy AK. Otodental syndrome: three familial case reports. Pediat. Dent 1998; 20(3): 208-11.

7. Cook RA, Cox JR, Jorgenson RJ. Otodental dysplasia: a five year study. Ear Hear 1981; 2: 90-94.

8. Aragão W. Respirador bucal. J. Ped. Boston 1998; 64(8): 349-52.

9. Felício CM. Fonoaudiologia Aplicada a Casos Odontológicos. Ed. Pancast; 1999. p. 40-46.

10. Marins RS. Síndrome do respirador bucal e modificação posturais em crianças e adolescentes: a importância da fisioterápica na equipe multidisciplinar. Fisio. em mov 2001; 14(1): p. 45-52.

11. Okeson JP. Tratamento das desordens temporomandibulares e oclusão. $4^{\circ}$ ed. São Paulo: Artes médicas; 2000. p. 190-200.

12. Costa D. Fisioterapia Respiratória Básica. São Paulo. Ed. Manole; 1999 p. 28-35.

13. Bianchini EMG. A cefalometria nas alterações miofuncionais orais: diagnóstico e tratamento fonoaudiológico. Pró-Fono São Paulo 1993; p. 27-28. 